Article

\title{
Resonant Rectifier ICs for Piezoelectric Energy Harvesting Using Low-Voltage Drop Diode Equivalents
}

\author{
Amad Ud Din, Seneke Chamith Chandrathna and Jong-Wook Lee * \\ Department of Electronics Engineering, Information and Communication System-on-Chip (SoC) Research \\ Center, Kyung Hee University, Yongin 17104, Korea; ammad@khu.ac.kr (A.U.D.); \\ b13chamith@gmail.com (S.C.C.) \\ * Correspondence: jwlee@khu.ac.kr; Tel.: +82-31-201-3730
}

Academic Editor: Vittorio M. N. Passaro

Received: 20 February 2017; Accepted: 17 April 2017; Published: 19 April 2017

\begin{abstract}
Herein, we present the design technique of a resonant rectifier for piezoelectric (PE) energy harvesting. We propose two diode equivalents to reduce the voltage drop in the rectifier operation, a minuscule-drop-diode equivalent (MDDE) and a low-drop-diode equivalent (LDDE). The diode equivalents are embedded in resonant rectifier integrated circuits (ICs), which use symmetric bias-flip to reduce the power used for charging and discharging the internal capacitance of a PE transducer. The self-startup function is supported by synchronously generating control pulses for the bias-flip from the PE transducer. Two resonant rectifier ICs, using both MDDE and LDDE, are fabricated in a $0.18 \mu \mathrm{m}$ CMOS process and their performances are characterized under external and self-power conditions. Under the external-power condition, the rectifier using LDDE delivers an output power $P_{\text {OUT }}$ of $564 \mu \mathrm{W}$ and a rectifier output voltage $V_{R E C T}$ of $3.36 \mathrm{~V}$ with a power transfer efficiency of $68.1 \%$. Under self-power conditions, the rectifier using MDDE delivers a $P_{\text {OUT }}$ of $288 \mu \mathrm{W}$ and a $V_{R E C T}$ of $2.4 \mathrm{~V}$ with a corresponding efficiency of $78.4 \%$. Using the proposed bias-flip technique, the power extraction capability of the proposed rectifier is 5.9 and 3.0 times higher than that of a conventional full-bridge rectifier.
\end{abstract}

Keywords: AC-DC converters; energy harvesting; piezoelectric; rectifier

\section{Introduction}

There is increasing demand for autonomous sensing devices, deployed in various applications, such as medical, healthcare, and environmental monitoring [1]. To enable uninterrupted data gathering from a large population of sensing devices, e.g., the Internet of Things (IoT), a long lifetime is critical. Although there are continued innovations in battery capacity, battery lifetime is still finite. To extend the lifetime of sensing devices, energy can be acquired from ambient sources. There exist various sources from which energy can be extracted, including thermal, solar, vibrations, and wind. Among those energy sources, vibrations can provide a relatively large amount of energy through highly-efficient piezoelectric $(\mathrm{PE})$ transducers.

The equivalent electrical model of a PE transducer is represented as a sinusoidal current source $I_{P}(t)=I_{P} \sin \left(\omega_{p} t\right)$ in parallel with a capacitor $C_{p}$ and a resistor $R_{p}$, where $\omega_{p}=2 \pi f_{p}$ is the angular frequency. In general, $R_{p}$ is very large during low-frequency transducer operation, and the open-circuit voltage can be expressed as $V_{p}=I_{P} / \omega_{p} C_{p}$. The output of a PE transducer is alternating current (AC) and, thus, needs conversion to direct current (DC). The commonly used AC-DC converters are full-bridge rectifiers (FBRs) and voltage doubler rectifiers (VDRs). Both FBR and VDR deliver a similar maximum output power when ideal diodes are used [2]. The operation of an FBR is well understood, which 
provides current for every half-cycle only after charging $C_{p}$ to $\pm\left(V_{R E C T}+2 V_{D}\right)$. Here, $V_{R E C T}$ is the rectified output voltage and $V_{D}$ is the diode voltage drop. The VDR provides current to the output only during the positive half-cycle. In the negative half-cycle, a diode in parallel with the PE transducer provides a path to discharge $C_{p}$ to the ground. During the positive half-cycle, $I_{P}$ only needs to charge $C_{p}$ from $-V_{D}$ to $\left(V_{R E C T}+V_{D}\right)$ before current can flow into the output.

In the rectifier, a commonly used figure-of-merit is the power transfer efficiency, which is defined as the ratio of the output power $P_{\text {OUT }}$ to the input power $P_{\mathrm{IN}}$, which can be delivered by the PE transducer. Rectifying a low voltage from a PE transducer may induce significant power losses due to the diode voltage drop. An effective way to increase the efficiency of the rectifier is (1) reducing the diode's voltage drop; and (2) increasing the input voltage by implementing the bias-flip strategy.

Figure 1 shows several reported techniques for improving the efficiency [2-6]. The switch-only rectifier is introduced to reduce the power to charge $C_{p}$ (not delivered to output) during the negative cycle of the VDR. In this approach, a switch $\mathrm{M}_{1}$ is shunted across the PE transducer, as shown in Figure 1a. The purpose of this switch is to discharge $C_{p}$ instantaneously when $I_{P}$ crosses zero. Since the switch is on at the zero crossing, the initial voltage to charge $C_{p}$ starts from 0 rather than $-V_{D}$. This modification reduces the charge which is not delivered to the output and increases the extracted power.

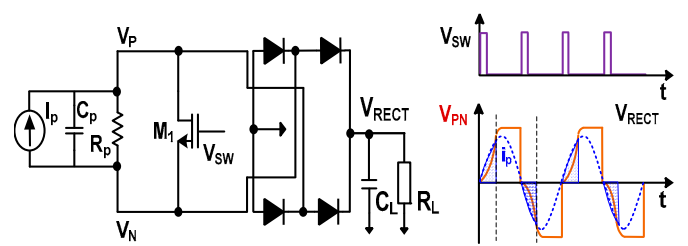

(a)

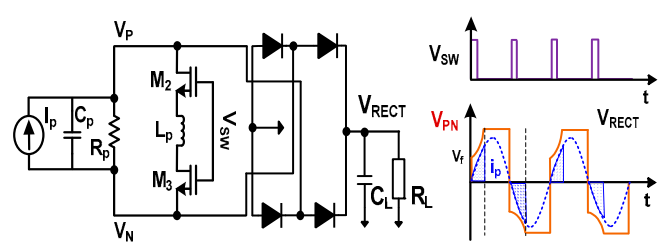

(b)

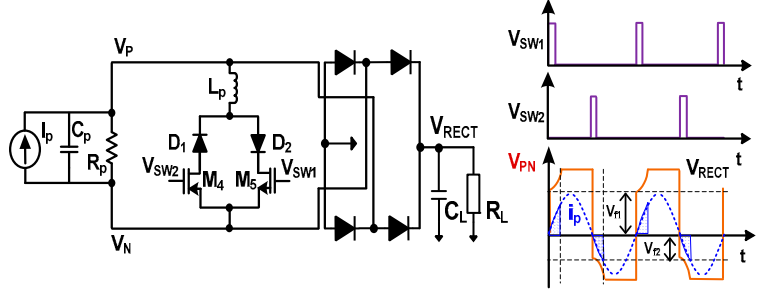

(c)

Figure 1. Schematics of the rectifiers for piezoelectric energy harvesting utilizing (a) switch-only; (b) bias-flip using an inductor; and (c) bias-flip using two switches and diodes with an inductor. The output load includes $C_{L}$ and $R_{L}$.

During the period when $C_{p}$ is charged, however, there is still a large portion of $I_{P}$ that is not delivered to the output. The highlighted portion of $I_{P}$, shown in Figure 1a, indicates the portion of $I_{P}$, which is used to charge $C_{p}$ from 0 to $\pm\left(V_{R E C T}+2 V_{D}\right)$. To reduce the charge, the work in [2] introduces a bias-flip technique, shown in Figure 1b. An inductor $L_{P}$ is shunted across the PE transducer through the switches realized with $\mathrm{M}_{2}$ and $\mathrm{M}_{3}$. When $I_{P}$ crosses zero, the pulse signal $V_{S W}$ briefly turns $\mathrm{M}_{2}$ and $\mathrm{M}_{3}$ on. At this time, the resonant loop formed by $C_{p}$ and $L_{P}$ flips the voltage, $V_{P N}=V_{P}-V_{N}$ across the transducer. Then, the charging starts from the flip-voltage $V_{f}$ rather than from $0 \mathrm{~V}$. Since flipping reduces the amount needed to charge $C_{p}$ from 0 to $V_{f}$, this technique increases the extracted power. However, we note that there exists power loss from the voltage drop of the two switches. In addition, the body diode of switches may be conducting for a large $V_{P N}$ (This observation also applies to $\mathrm{M}_{1}$ in Figure 1a. To reduce the voltage drop, current paths for positive and negative cycles are split [4-6]. Sharing a single inductor $L_{P}$ as shown in Figure 1c, this approach provides two branches for the bias-flip using two diodes and two shunt switches. The transducer voltage is flipped alternatively through two paths. Then, the voltage drop by the switch is reduced from two to one, but with an additional diode voltage drop. The drawback of this approach is that the two bias-flip voltages, $V_{f 1}$ 
and $V_{f 2}$ for positive and negative cycles, respectively, are different, i.e., $V_{f 1} \neq V_{f 2}$. This is because the impedance at $V_{P}$ and $V_{N}$ seen from the flipping path is different, and we observe asymmetric flipping in the waveform. The asymmetry results in fluctuation of the extracted power and increased output ripple.

The diode voltage drop $V_{D}$ existing in the rectifier loop is the third reason for the low efficiency. The $V_{D}$ drop can be reduced by adding a bias voltage between the gate and drain terminal of a transistor [7]. To generate the bias voltages for a multi-stage rectifier, an extra bias distributor is required, which increases circuit complexity and the losses associated with it. In [3], an active diode, based on an op-amp with a pre-set DC offset, is used to reduce $V_{D}$ and the leakage current. Another method to reduce $V_{D}$ is by using a comparator-controlled switch [8]. This approach requires approximately one threshold voltage $V_{T H}$ plus two overdrive voltages to power up, limiting the input voltage for start-up to $1.2 \mathrm{~V}$ using a $0.35 \mu \mathrm{m}$ CMOS process. Usually, the comparator is powered up from the output storage capacitor. If there is not enough voltage to power up, the comparator will not be readily activated.

Herein, we propose two resonant rectifiers using low-voltage drop diode equivalents to overcome the limitations that exist in previous studies. We propose two diode equivalents, a minuscule-drop-diode equivalent (MDDE) and a low-drop-diode equivalent (LDDE), which effectively reduces the $V_{D}$ of the rectifying stage. The diode equivalents are efficiently combined with a symmetric and low-loss resonant loop to realize the bias-flip technique. Harnessing MDDE and LDDE, two resonant rectifier integrated circuits (ICs) having self-startup capabilities are designed. To improve the efficiency under the self-power condition, the rectifier using MDDE includes synchronous bootstrap pulse generators (SBPGs). The SBPG provides boosted bias-flipping pulses that are synchronized with the frequency of the PE transducer. Two resonant rectifier ICs using both MDDE and LDDE, are fabricated in a $0.18 \mu \mathrm{m}$ CMOS process. The rectifier using LDDE shows measured $P_{\text {OUT }}$ of $564 \mu \mathrm{W}$ under an external-powered condition with a corresponding efficiency of $68.1 \%$. The rectifier using MDDE shows enhanced efficiency under the self-powered condition. It delivers a $P_{\text {OUT }}$ of $288 \mu \mathrm{W}$ with a corresponding efficiency of $78.4 \%$ and this result compares favorably with results from previous works.

\section{Design}

For an energy harvester, the capability for self-startup is one of the critical functions and several techniques have been reported [9-12]. In [9], the authors introduce a cold startup technique using a transformer. For high voltage boosting, this approach needs a transformer with a large turn ratio, which can increase the overall size of the harvester. In [10], the authors propose a mechanical switch that provides an instant power jerk to kick start the harvester. In [11], the authors present a low-voltage startup technique using a $V_{T H}$-tuned oscillator and a capacitor pass-on technique. Although a low startup voltage of $95 \mathrm{mV}$ is achieved, the drawback is that this approach requires external programming of a body voltage after fabrication. In [12], a charge pump with a switched body-biasing technique is presented. Since the body terminal of a transistor is connected to a high voltage when it is turned off, the reverse leakage is effectively suppressed. In these previous works, except [11], the self-startup function, which is vital to autonomous operation, is not fully supported. In this work, we embed a simple, yet efficient, approach for self-startup into the two resonant rectifiers.

\subsection{Resonant Rectifier Using LDDE}

Figure 2a shows the block diagram of the resonant rectifier IC using LDDE. The rectifier consists of a three-stage voltage multiplier (VM), an oscillator (OSC), a bootstrap pulse generator (BPG), a symmetric bias-flip circuit, and a full-bridge rectifying stage. The BPG provides the bootstrapped pulse signals $V_{\mathrm{SW} 1}$ and $V_{\mathrm{SW} 2}$ for the bias-flip circuit. The clock (CLK) signal for the BPG is generated by the OSC with a frequency that can be tuned using a ring oscillator. The supply voltage of the OSC is driven by the output $V_{\mathrm{VM}}$ of the voltage multiplier shown in Figure $2 \mathrm{~b}$. For efficient operation, the 
VM uses Schottky diodes $\left(\mathrm{D}_{\mathrm{V} 1}-\mathrm{D}_{\mathrm{V} 6}\right)$ realized in a standard CMOS process, which shows a low $V_{D}$ of $160 \mathrm{mV}$ at $1 \mu \mathrm{A}$ [13]. Since the VM and OSC are powered from the PE transducer, the rectifier provides the self-startup function.

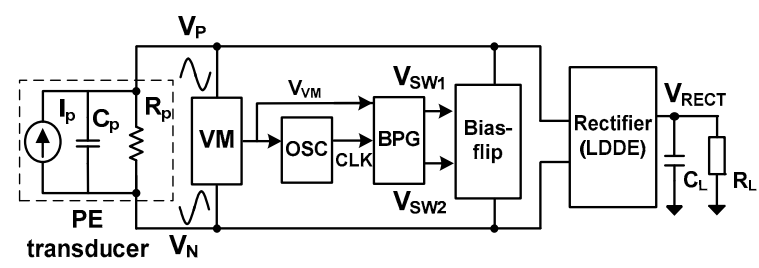

(a)

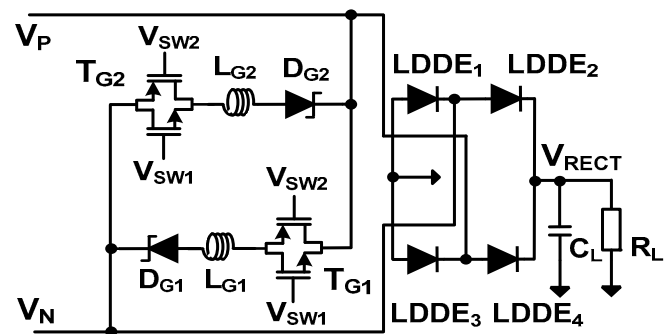

(c)

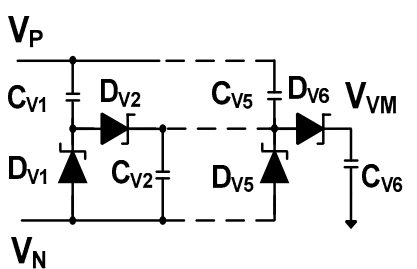

(b)

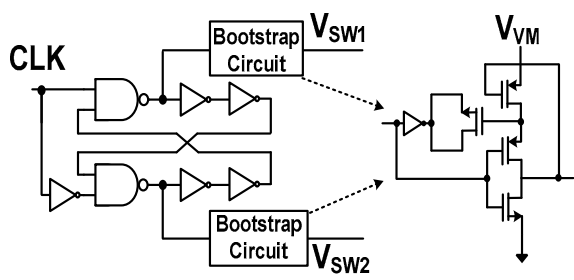

(d)

Figure 2. (a) Block diagram of the proposed resonant rectifier IC using LDDE; (b) voltage multiplier; (c) bootstrap pulse generator; and (d) the symmetric bias-flip circuit and rectifying stage using LDDEs.

Figure 2c shows the schematic of the BPG which generates $V_{S W 1}$ and $V_{S W 2}$. The amplitudes of these signals are increased to almost $2 V_{V M}$, which provide the high overdrive voltage needed to fully turn on the switches in the bias-flip circuit, shown in Figure 2d. The bias-flip circuit consists of Schottky diodes $\left(\mathrm{D}_{\mathrm{G} 1}, \mathrm{D}_{\mathrm{G} 2}\right)$, inductors $\left(\mathrm{L}_{\mathrm{G} 1}, \mathrm{~L}_{\mathrm{G} 2}\right)$, and transmission $(\mathrm{T})$-gate transistors $\left(\mathrm{T}_{\mathrm{G} 1}, \mathrm{~T}_{\mathrm{G} 2}\right)$. The T-gate is used to reduce the on-resistance of the switch [14]. The size of NMOS and PMOS transistors in the T-gate are $\mathrm{W} / \mathrm{L}=1000 \mu \mathrm{m} / 0.2 \mu \mathrm{m}$ and $2000 \mu \mathrm{m} / 0.18 \mu \mathrm{m}$, respectively, with values optimized by using a circuit simulator. When $I_{P}$ crosses zero, the bias-flip circuit changes the polarity of $V_{P N}$ using two separate paths. The positive cycle uses the path formed by $\mathrm{T}_{\mathrm{G} 1}, \mathrm{~L}_{\mathrm{G} 1}$, and $\mathrm{D}_{\mathrm{G} 1}$, while the path formed by $\mathrm{T}_{\mathrm{G} 2}, \mathrm{~L}_{\mathrm{G} 2}$, and $\mathrm{D}_{\mathrm{G} 2}$ is used in the negative cycle. Inductors are bulky and expensive; the bias-flip circuit shown in Figure 2d is improved to use only one inductor (see Section 2.2).

Figure 3 shows a detailed schematic of the rectifying stage using four LDDEs. LDDE $_{1,3}$ are NMOS-based LDDEs and the LDDE 2,4 are PMOS-based LDDEs. When $V_{P}>V_{N}, \mathrm{LDDE}_{1}$ and LDDE 4 conduct and form a closed loop. $\mathrm{LDDE}_{4}$ consists of a main transmission transistor $\mathrm{MP}_{1}$ and control circuit $\left(\mathrm{MP}_{2}, \mathrm{MN}_{1}\right.$, and $\left.\mathrm{MN}_{2}\right)$. The $\mathrm{LDDE}_{1}$ consists of the main transistor $\mathrm{MN}_{3}$ and control circuit $\left(\mathrm{MN}_{4}, \mathrm{MP}_{3}\right.$, and $\left.\mathrm{MP}_{4}\right)$. In a previous work [15], the control circuit for the LDDE is implemented using discrete bipolar junction transistors (BJTs). In this work, we remove the base current of the BJT using metal-oxide field effect transistors (MOSFETs) realized in IC technology. A voltage polarity sense circuit is formed by the diodes $\mathrm{D}_{\mathrm{S} 1}-\mathrm{D}_{\mathrm{S} 4}$ and $C_{S}$. The circuit detects the positive $\left(V_{P}>V_{N}\right)$ and negative $\left(V_{P}<V_{N}\right)$ cycles using four terminal voltages, $V_{R 1}, V_{R 2}, V_{C 1}$, and $V_{C 2}$. Using the four voltages, the sense circuit controls the conduction of the main transistor while blocking reverse leakage current. The voltage at nodes $V_{C 1}$ and $V_{C 2}$ control the conduction of $\mathrm{LDDE}_{1}$ and $\mathrm{LDDE}_{4}$ in the positive cycle (LDDE 2 and $\mathrm{LDDE}_{3}$ in the negative cycle), respectively. The voltage at nodes $V_{R 1}$ and $V_{R 2}$ blocks reverse conduction of $\mathrm{LDDE}_{4}$ and $\mathrm{LDDE}_{1}$ in the negative cycle $\left(\mathrm{LDDE}_{3}\right.$ and $\mathrm{LDDE}_{2}$ in the positive cycle), respectively.

The operation of the LDDE is described using four states, shown in Figure $3 \mathrm{~b}$. When $I_{P}$ crosses zero from negative to positive, $D_{S 2}$ and $D_{S 4}$ are forward-biased forming the conducting path $D_{S 2}-C_{S}-D_{S 4}$. The terminal voltages detected by the sense circuit satisfy the condition $\left(V_{C 1}=V_{P}\right)>\left(V_{R 2}=V_{P}-V_{D 1}\right)$ 
$>\left(V_{R 1}=V_{N}+V_{D 1}\right)>\left(V_{C 2}=V_{N}\right)$, where $V_{\mathrm{D} 1}$ is the forward voltage drop of a diode in the sense circuit. We consider four operation states for $\mathrm{LDDE}_{4}$ as follows.

(1) State-1: In the positive cycle when $V_{\mathrm{P}}>V_{\mathrm{N}}$, we have the condition of $\left(V_{P}=V_{C 1}\right)>\left(V_{C 2}=V_{N}\right)$. Terminal $V_{C 2}$ is connected to the negative terminal $V_{N}$ of the PE transducer through $\mathrm{MN}_{2}$. Then $\mathrm{MP}_{2}$ turns on and subsequently turns on $\mathrm{MN}_{2}$, as well. The $C_{S G}$ of $\mathrm{MP}_{1}$ is charged by $V_{\mathrm{PN}}$.

(2) State-2: The source and gate terminals of $\mathrm{MP}_{1}$ are approximately $V_{P}$ and $V_{N}+V_{D S, M N 2}$, respectively. Here, $V_{D S, M N 2}$ is the drain-source voltage of $\mathrm{MN}_{2}$. The voltage at node $V_{P}$ keeps increasing. Then, $\mathrm{MP}_{1}$ begins conducting when $V_{S G}>\left|V_{T H}\right|$. The voltage across $\mathrm{C}_{\mathrm{SG}}$ of $\mathrm{MP}_{1}$ keeps increasing and $\mathrm{MP}_{1}$ enters the triode from the saturation mode. Using the rectifier operation, $V_{\mathrm{RECT}}$ increases. Then, the condition $\left(V_{P N}-V_{D S, M N 2}-\left|V_{T H}\right|\right)>\left(V_{P}-V_{R E C T}\right)$ allows $\mathrm{MP}_{1}$ to enter the triode mode, which can be written as $V_{R E C T}>\left(V_{N}+\left|V_{T H}\right|+V_{D S, M N 2}\right)$.

(3) State-3: When the $V_{S D}$ of $\mathrm{MP}_{1}$ decreases by increasing $V_{\mathrm{RECT}}$, it turns $\mathrm{MP}_{2}$ off. When $\mathrm{MP}_{2}$ is off, $\mathrm{C}_{S G}$ of $\mathrm{MP}_{1}$ stops charging and it maintains the $V_{S G}$ of $\mathrm{MP}_{1}$. This allows $\mathrm{MP}_{1}$ to continue conducting in the triode mode. When $\mathrm{MP}_{2}$ is off, the gate of $\mathrm{MN}_{2}$ has no path to conduct and, therefore, $\mathrm{MN}_{2}$ is kept on. This state is different from the BJT version of the LDDE [15]; the base current of a BJT provides a path to discharge while the MOSFET $\mathrm{MN}_{2}$ is kept on.

(4) State-4: When $i_{p}$ changes direction $\left(V_{P}<V_{N}\right)$, the current direction in the sense circuit is reversed. Then, the terminal voltages detected by the sense circuit satisfy the condition $\left(V_{C 2}=V_{N}\right)>$ $\left(V_{R 1}=V_{N}-V_{D 1}\right)>\left(V_{R 2}=V_{P}+V_{D 1}\right)>\left(V_{C 1}=V_{P}\right)$. This condition turns on $\mathrm{MN}_{1}$. By discharging the $C_{G D}$ of $\mathrm{MP}_{1}, \mathrm{MN}_{1}$ subsequently turns off $\mathrm{MP}_{1}$ to prevent reverse leakage. Since $V_{C 2}$ is positive and increasing, $\mathrm{MN}_{2}$ is turned off, which prevents the discharging of $V_{R E C T}$ through $\mathrm{MN}_{1}$.

In the case of $V_{P}<V_{N}, \mathrm{LDDE}_{2}$ and $\mathrm{LDDE}_{3}$ conduct. During the zero-crossing of $I_{P}$ from positive to negative, $D_{S 1}$ and $D_{S 3}$ are forward-biased, forming the conduction path $D_{S_{3}}-C_{S}-D_{S 1}$. The operation of $\mathrm{LDDE}_{2}$ and $\mathrm{LDDE}_{3}$ follow four states in a manner similar to that described above. As other sensor-free bias-flip rectifiers, the frequency control method of the rectifier using LDDE is not adaptive to the $f_{p}$ of PE transducer. If $f_{p}$ changes by aging or other reasons, the bias-flip operation may not occur at the exact zero crossing of $I_{P}$. To handle this issue, a simple yet effective frequency tracking method is implemented in the rectifier using MDDE, as explained in the next section.

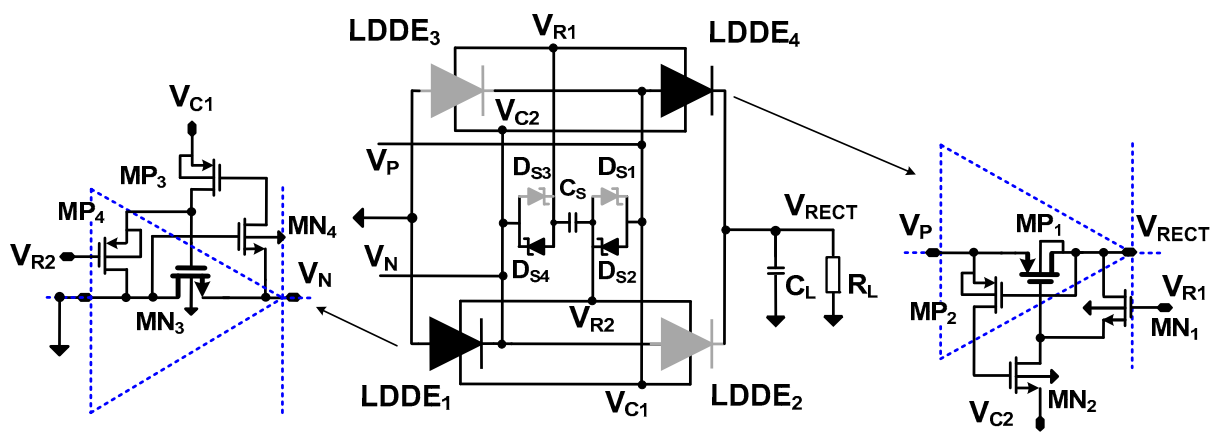

(a)

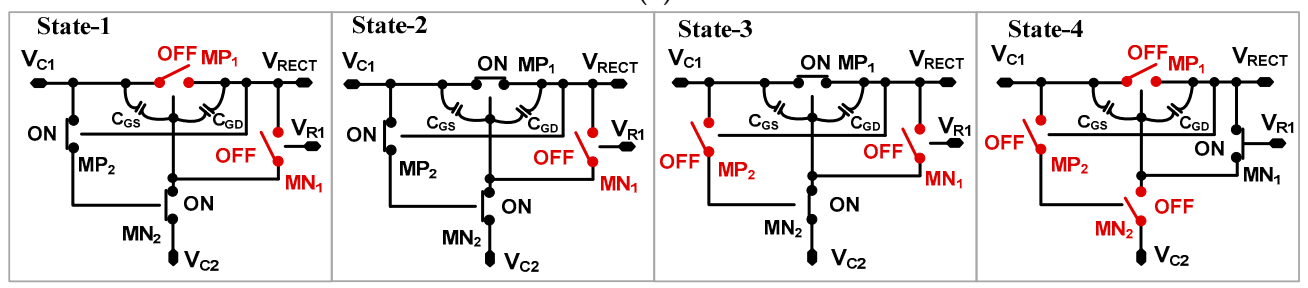

(b)

Figure 3. (a) Schematic of the rectifier loop using LDDEs; and (b) four operation states described using $\mathrm{LDDE}_{4}$. 


\subsection{Resonant Rectifier Using MDDE}

Figure 4a shows the block diagram of the resonant rectifier using MDDE. The rectifier IC includes two synchronous bootstrap pulse generators (SBPGs), dual voltage doublers, a symmetric bias-flip circuit, and a rectifying stage using MDDE. Instead of using VM and OSC for frequency generation, the pulse signals $V_{S W 1}$ and $V_{S W 2}$ for the bias-flip circuit are directly derived from the PE transducer. For efficient bias-flipping, the $V_{S W 1}$ and $V_{S W 2}$ are bootstrapped by the SBPG, which is driven by the output $V_{\mathrm{DBL}}$ from a voltage doubler. The dual voltage doublers are realized using the Schottky diodes $\mathrm{D}_{\mathrm{D} 1}-\mathrm{D}_{\mathrm{D} 4}$. Without an external power supply, the SBPG and doublers are driven by the PE transducer, realizing the self-startup function.

Figure $4 \mathrm{~b}$ shows a schematic of the SBPG. The two SBPGs operate in a complementary manner, generating two opposite phase pulse signals, $V_{S W 1}$ and $V_{S W 2}$. In the SBPG, $V_{P}$ is compared with $V_{N}$ and the output of the comparator $C_{M P 1,2}$ drives the BPG. In this way, the voltages $V_{S W 1}$ and $V_{S W 2}$ for the bias-flip circuit are generated in sync with the $f_{\mathrm{p}}$ of the PE transducer. The comparator $\mathrm{C}_{\mathrm{MP} 1,2}$ is realized using a differential amplifier with a latched load for increased gain. It achieves an open-loop gain of $35 \mathrm{~dB}$ by consuming $770 \mathrm{nA}$. Two diodes, $\mathrm{D}_{\mathrm{C} 1}$ and $\mathrm{D}_{\mathrm{C} 2}$, are used to prevent reverse leakage current. By the BPG, the amplitudes of $V_{S W 1}$ and $V_{S W 2}$ are increased by about twice that of $V_{D B L}$, which effectively flips the voltage across the nodes $V_{P}$ and $V_{N}$.

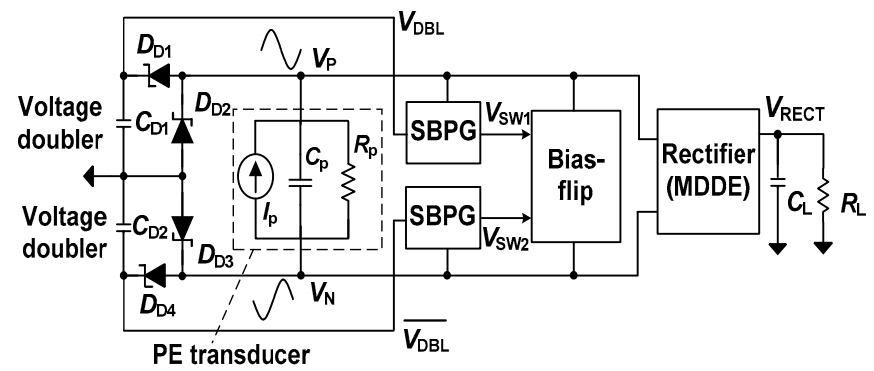

(a)

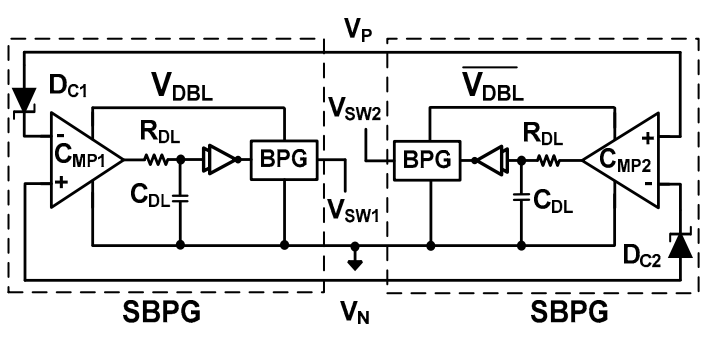

(b)

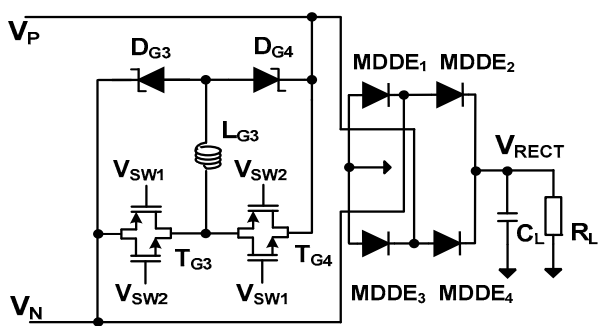

(c)

Figure 4. (a) Block diagram of the proposed resonant rectifier IC using MDDE; (b) synchronous bootstrap pulse generator; and (c) bias-flip circuit and rectifying stage using MDDE.

To compensate the time delay between $V_{S W 1,2}$ and $V_{P N}$, a delay line consisting of $R_{D L}$ and $C_{D L}$ is added. This allows fine tuning of the delay, which aligns the pulses $V_{S W 1}$ and $V_{S W 2}$ with the zero crossing of $I_{P}$. Due to the power constraint for self-startup, the values of $R_{D L}$ and $C_{D L}$, which depend on transducer parameters $\left(R_{L}, I_{P}\right.$ and $\left.f_{P}\right)$, are externally controlled (Table 1$)$. We perform circuit simulations and the results show that the $f_{P}$ from 100 to $800 \mathrm{~Hz}$ can be handled using this approach. The minimum delay determined by the comparator, a buffer, and BPG sets the $800 \mathrm{~Hz}$ as the maximum input frequency. Figure 4c shows the schematic of the bias-flip circuit and the rectifying stage using the MDDEs. To control the path for bias-flip, the Schottky diodes $\mathrm{D}_{\mathrm{G} 3}$ and $\mathrm{D}_{\mathrm{G} 4}$ are used. Using a single inductor $\mathrm{L}_{\mathrm{G} 3}$, two separate and symmetric paths are created for the positive (a path along $\mathrm{T}_{\mathrm{G} 4}, \mathrm{~L}_{\mathrm{G} 3}$, and $\mathrm{D}_{\mathrm{G} 3}$ ) and negative (a path along $\mathrm{T}_{\mathrm{G} 3}, \mathrm{~L}_{\mathrm{G} 3}$ and $\mathrm{D}_{\mathrm{G} 4}$ ) cycles. Compared to the bias-flip circuit for the rectifier using LDDE, the circuit for the MDDE is improved to use one shared inductor. 
Table 1. Values of the delay line depending on $R_{L}, I_{P}$, and $f_{P}$.

\begin{tabular}{|c|c|c|c|c|c|c|c|c|c|c|}
\hline \multirow{2}{*}{\multicolumn{2}{|c|}{$\begin{array}{c}f_{p}(\mathrm{~Hz}) \\
R_{L}(\mathrm{~K} \Omega)\end{array}$}} & \multicolumn{3}{|c|}{200} & \multicolumn{3}{|c|}{300} & \multicolumn{3}{|c|}{400} \\
\hline & & 100 & 50 & 20 & 100 & 50 & 20 & 100 & 50 & 20 \\
\hline \multicolumn{11}{|c|}{$R_{D L}(\mathrm{M} \Omega) / C_{D L}(\mathrm{nF})$} \\
\hline \multirow{4}{*}{$I_{P}(\mu \mathrm{A})$} & 200 & $8 / 1$ & $8 / 1$ & $10 / 1$ & $8 / 1$ & $8 / 1$ & $8 / 1$ & $8 / 1$ & $8 / 1$ & $8 / 1$ \\
\hline & 300 & $10 / 1$ & $14 / 1$ & $12 / 1$ & $8 / 1$ & $4 / 1.5$ & $4 / 1.5$ & $5 / 0.5$ & $5 / 0.5$ & $5 / 0.5$ \\
\hline & 400 & $10 / 1$ & $14 / 1$ & $14 / 1$ & $8 / 1$ & $8 / 1$ & $5 / 1$ & $8 / 0.5$ & $8 / 0.5$ & $3 / 1.2$ \\
\hline & 600 & $16 / 1$ & $16 / 1$ & $14 / 1$ & $8 / 1.5$ & $8 / 1.5$ & $7 / 1.5$ & $8 / 1$ & $8 / 1$ & $5 / 1.2$ \\
\hline
\end{tabular}

Figure 5 shows the operation of the rectifying stage using MDDEs. The bridge-type stage consists of two PMOS and NMOS-based MDDEs. MDDE 2,4 are PMOS-based MDDEs, where $\mathrm{TP}_{2}$ and $\mathrm{TP}_{4}$ are the main transmission transistors. $\mathrm{MDDE}_{1,3}$ are NMOS-based MDDEs, where $\mathrm{TN}_{1}$ and $\mathrm{TN}_{3}$ are the main transistors. The control circuit, which consists of a diode and a transistor in each MDDE, reduces the $V_{D}$ of the main transistor via the deep-triode mode while blocking the reverse leakage current. In the positive cycle $\left(V_{P}>V_{N}\right), \mathrm{MDDE}_{2}$ and $\mathrm{MDDE}_{3}$ close the loop, as shown in Figure 5a. The diode $\mathrm{D}_{2}$ is forward biased, which turns on $\mathrm{N}_{2}$. At this time, the gate of $\mathrm{TP}_{2}$ is connected to $V_{N}$ through $\mathrm{N}_{2}$, which turns on $\mathrm{TP}_{2}$. Since $V_{N}$ is negative, it also turns on $\mathrm{P}_{3}$ and $\mathrm{D}_{3}$. The $V_{\mathrm{SG}}$ of $\mathrm{TP}_{2}$ is determined by the voltage at the gate $\left(V_{N}+V_{D S, N 2}\right)$ and source $\left(V_{R E C T}\right)$. With the condition $\left(V_{R E C T}-V_{N}-V_{D S, N 2}\right)>\left|V_{T H}\right|, \mathrm{TP}_{2}$ is turned on. The $V_{G S}$ of $\mathrm{TN}_{3}$ is determined by the voltage at the gate $\left(V_{P}-V_{S D, P 3}\right)$ and source $\left(V_{R E C T}-V_{D, R L}\right)$, where $V_{S D, P 3}$ and $V_{D, R L}$ are the source-drain voltage of $\mathrm{P}_{3}$ and the voltage drop across $R_{L}$, respectively. With the condition $\left(V_{P}-V_{S D, P 3}-V_{R E C T}+V_{D, R L}\right)$ $>V_{T H}$, the $\mathrm{TN}_{3}$ connects between $V_{N}$ and $V_{R E C T}$, closing the loop.

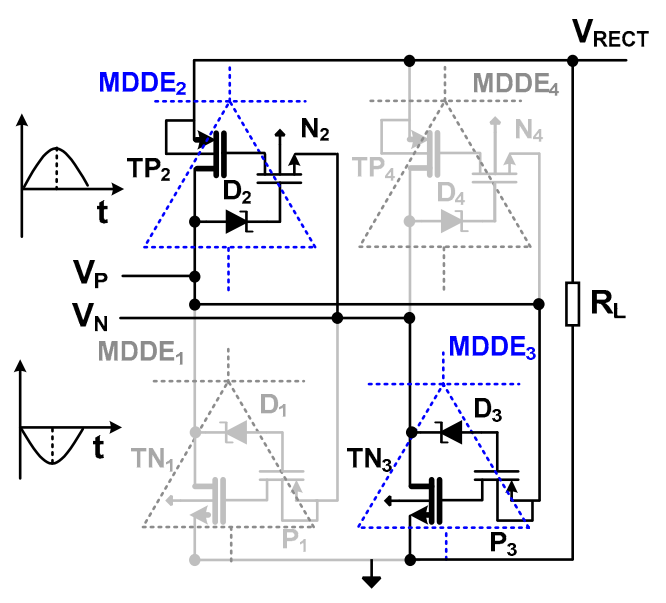

(a)

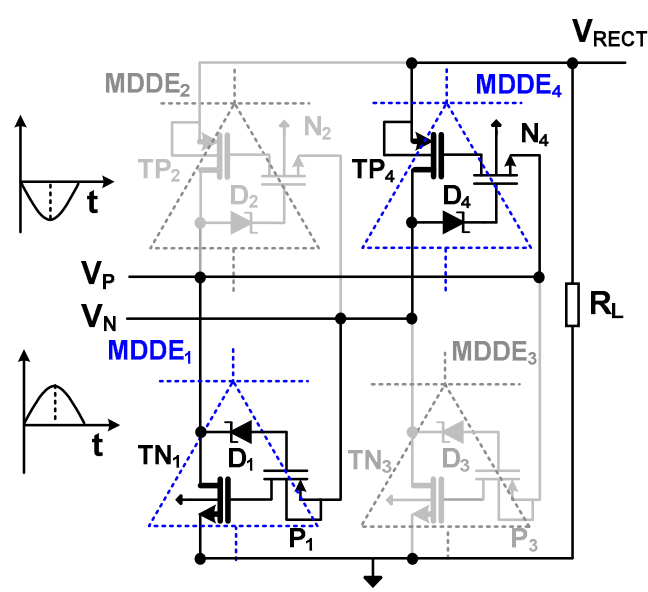

(b)

Figure 5. Schematic of the rectifier loop using MDDE and operation during (a) positive and (b) negative cycles.

Next, we find the condition for $\mathrm{TP}_{2}$ and $\mathrm{TN}_{3}$ to operate in triode mode. In $\mathrm{TP}_{2}$, we observe that the source-drain voltage is $V_{R E C T}-V_{P}$ and the source-gate voltage is $V_{R E C T}-\left(V_{N}+V_{D S, N 2}\right)$. Therefore, the condition $V_{P N}>\left(\left|V_{T H}\right|+V_{D S, N 2}\right)$ allows deep-triode operation of $\mathrm{TP}_{2} . \mathrm{For}_{\mathrm{TN}}$, we observe that the drain-source voltage is $V_{N}-\left(V_{R E C T}-V_{D, R L}\right)$ and the gate-source voltage is $\left(V_{P}-V_{S D, P 3}\right)-\left(V_{R E C T}-V_{D, R L}\right)$. Then, the condition $V_{P N}>>\left(V_{T H}+V_{S D, P 3}\right)$ allows deep-triode mode operation for $\mathrm{TN}_{2}$. In the negative cycle $\left(V_{P}<V_{N}\right), \mathrm{D}_{2}$ and $\mathrm{D}_{3}$ are reverse biased, and the voltage at the source terminal of $\mathrm{N}_{2}$ is $V_{N}>0$ (for $\mathrm{P}_{3}$, it is $V_{P}<0$ ). Therefore, both $\mathrm{N}_{2}$ and $\mathrm{P}_{3}$ are kept off and the reverse leakage through $\mathrm{TP}_{2}$ and $\mathrm{TN}_{3}$ is blocked. The operation of $\mathrm{MDDE}_{1}$ and $\mathrm{MDDE}_{4}$ in the negative cycle $\left(V_{P}<V_{N}\right)$ can be similarly described, as shown in Figure $5 \mathrm{~b}$. 
Figure 6 shows the comparison of $V_{D}$ of the LDDE and MDDE as a function of $I_{P}$. The two $R_{L}$ values and the size of the main transistor are chosen to match the result in [15]. Since the control circuit does not fully turn on with small $I_{P}$ values, the results show that the $V_{D}$ of both diode equivalents increases in the small $I_{P}$ range from 20 to $40 \mu \mathrm{A}$. When $I_{P}$ increases above $60 \mu \mathrm{A}, V_{D}$ increases with $I_{P}$. The LDDE has a narrow window in the $I_{P}$ range from 30 to $40 \mu \mathrm{A}$. In the case of MDDE, the $V_{D}$ is below $50 \mathrm{mV}$ in the $I_{P}$ range from 30 to $60 \mu \mathrm{A}$. In order to investigate the performance for different $\mathrm{PE}$ transducer parameters, Figure $6 \mathrm{~b}$ shows the comparison of $V_{D}$ of the LDDE and MDDE for the different periphery. For a PE transducer having $I_{P}=600 \mu \mathrm{A}$, the $V_{D}$ is $230 \mathrm{mV}$ and $360 \mathrm{mV}$ in case of MDDE and LDDE having the same size, respectively. The results show that the MDDE shows an overall smaller $V_{\mathrm{D}}$ than that of the LDDE over a broad range of $I_{P}$. The LDDE use three extra transistors to control the on-resistance of the main conducting transistor. In the case of the MDDE, the control is achieved using a transistor and a diode, which makes it simple, with a low loss.

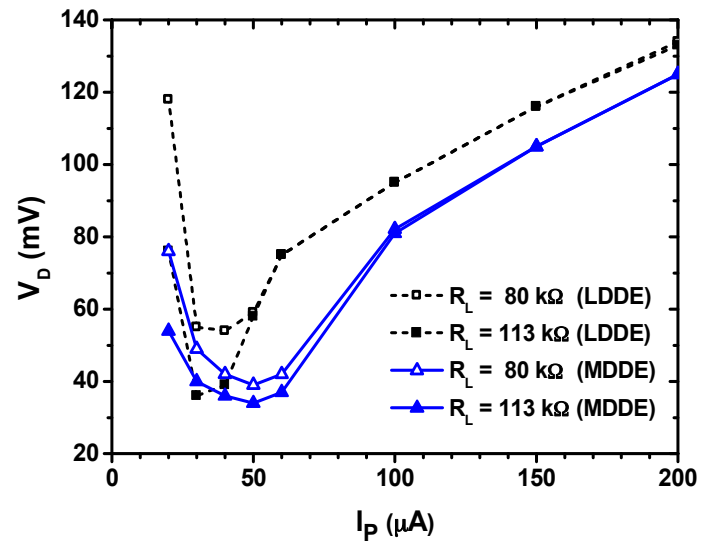

(a)

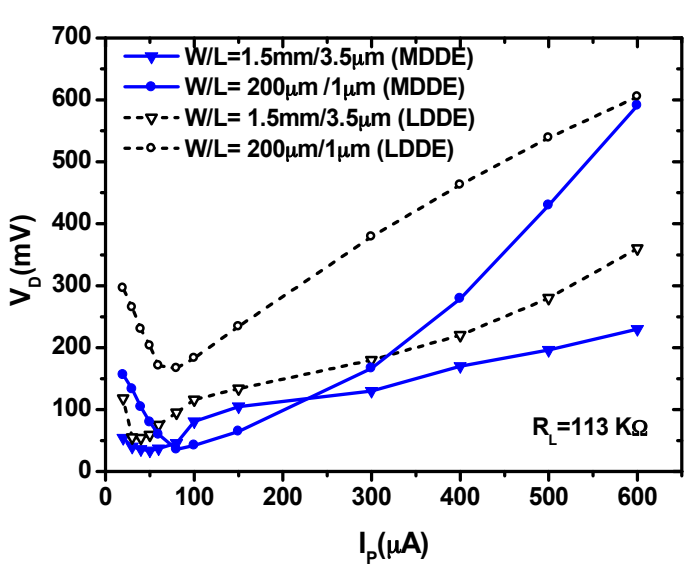

(b)

Figure 6. Comparison of the diode voltage drops as a function of $I_{P}$ for (a) different loads; and (b) periphery $(\mathrm{W} / \mathrm{L})$.

\subsection{Loss Calculation}

Figure 7 shows the key waveforms of the resonant rectifier. When the PE element starts providing $I_{P}$, the rectifier enters a startup state. In this state, the BPG starts generating $V_{S W 1}$ and $V_{S W 2}$, which have amplitudes that increase with $V_{P N}$. A steady-state is assumed after $t_{1}$. Just before time $t_{1}, C_{p}$ is pre-recharged to $-\left(V_{R E C T}+2 V_{D}\right)$. At time $t_{1}, I_{P}$ changes direction and the bias-flip operation allows the charging of $C_{p}$ from $V_{f}$ to $\left(V_{R E C T}+2 V_{D}\right)$ until $t_{2}$. During this period, the output current $I_{\mathrm{o}}$ starts flowing to the load. In the negative cycle, $C_{p}$ is discharged from $-V_{f}$ to $-\left(V_{R E C T}+2 V_{D}\right)$. The effectiveness of bias-flip is usually expressed using a flipping efficiency $\eta_{f}$, defined as:

$$
\eta_{f}=\frac{V_{f}+V_{R E C T}}{2 V_{R E C T}}
$$

The amount of charge $Q_{c p}$ lost due to charging $C_{p}$ during time interval $\left[t_{1}, t_{2}\right]$ can be expressed as:

$$
Q_{C p}=\left[V_{R E C T}+2 V_{D}-V_{f}\right] C_{p}=\left[V_{R E C T}+2 V_{D}-V_{R E C T}\left(2 \eta_{f}-1\right)\right] C_{p}
$$

Next, we consider the charge lost across $R_{p}$ in the time interval $\left[t_{1}, t_{\pi}\right]$. Since $V_{P N}$ varies during the time interval, we consider two cases of charge losses, $Q_{R p 1}$ during $\left[t_{1}, t_{2}\right]$ and $Q_{R p 2}$ during $\left[t_{2}, t_{\pi}\right]$, given by:

$$
Q_{R p}=Q_{R p 1}+Q_{R p 2}=\int_{t 1}^{t 2} \frac{V_{P N}(t)}{R_{p}} d t+\int_{t 2}^{t \pi} \frac{V_{P N}(t)}{R_{p}} d t
$$


During the time interval $\left[t_{1}, t_{2}\right], V_{f}$ is inverted via a bias-flip. In this period, $V_{P N}(t)$ can be obtained by integrating $I_{P}(t)$ as:

$$
V_{P N}(t)=\frac{1}{C_{p}} \int_{t 1}^{t} I_{p} \sin \omega t d t-V_{f}\left(t_{1}\right)=\frac{I_{p}}{\omega C_{p}}\left(\cos \omega t_{1}-\cos \omega t\right)-V_{f}\left(t_{1}\right)
$$

Applying the boundary conditions $V_{f}=V_{R E C T}\left(2 \eta_{f}-1\right)$ and $\omega t_{1} \cong 0$, Equation (4) can be expressed as:

$$
V_{P N}(t)=V_{p}(1-\cos \omega t)-V_{R E C T}\left(2 \eta_{f}-1\right)
$$

where $V_{P}=I_{P} /\left(\omega_{p} C_{p}\right)$ is the open-circuit voltage. Using Equation (5), $Q_{R p 1}$ is obtained as:

$$
Q_{R p 1}=\int_{t 1}^{t 2} \frac{V_{p}(1-\cos \omega t)-V_{R E C T}\left(2 \eta_{f}-1\right)}{R_{p}} d t \cong \frac{V_{p}}{\omega R_{p}}\left(\omega t_{2}-\sin \omega t_{2}\right)-\frac{V_{R E C T}}{\omega R_{p}}\left(2 \eta_{f}-1\right) \omega t_{2}
$$

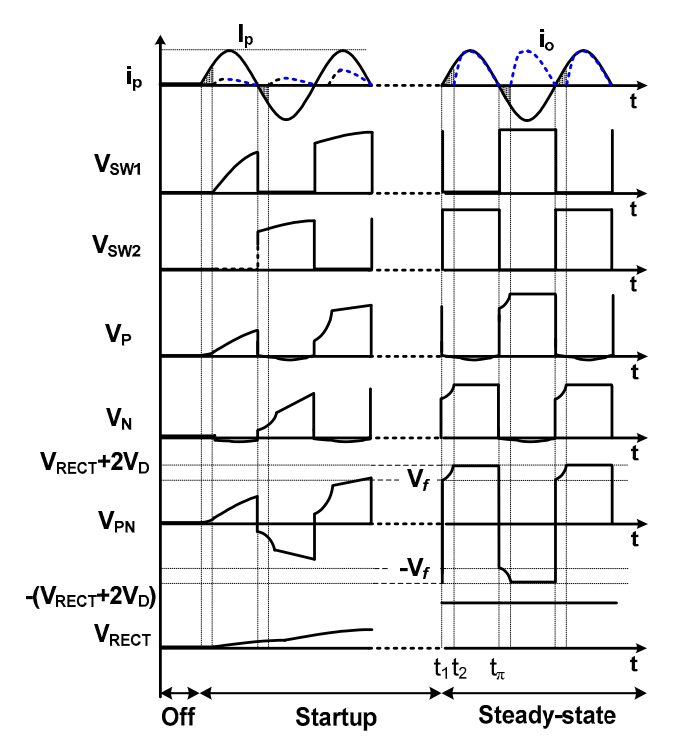

Figure 7. Key waveforms of the resonant rectifier.

To find $Q_{R p 2}$ during the time interval $\left[t_{2}, t_{\pi}\right]$, we need the value of $\omega t_{2}$ and, thus, use the following relationship:

$$
I_{p} \sin \omega t=C_{p} \frac{d V_{p}}{d t}=\omega C_{p} \frac{d V_{p}}{d \omega t}
$$

Integrating Equation (7) over the time interval $\left[t_{1}, t_{2}\right]$ when bias-flipping is performed, we obtain:

$$
V_{p}\left(-\cos \omega t_{2}+\cos \omega t_{1}\right)=V_{p}\left(t_{2}\right)-V_{p}\left(t_{1}\right)
$$

The values of $V_{p}$ can be obtained from the waveform, which are $V_{p}\left(t_{1}\right)=V_{f}$ and $V_{p}\left(t_{2}\right)=\left(V_{R E C T}+2 V_{D}\right)$. Then, Equation (8) can be written as:

$$
t_{2}=\frac{1}{\omega} \cos ^{-1}\left(\frac{V_{p}-2 V_{R E C T}-2 V_{D}+V_{R E C T} 2 \eta_{f}}{V_{p}}\right)
$$

Using Equation (9), $Q_{R p 2}$ is obtained as:

$$
Q_{R p 2}=\frac{\left(V_{R E C T}+2 V_{D}\right)}{R_{p}}\left(t_{\pi}-t_{2}\right)
$$

where $t_{\pi}=\pi / \omega$. 
The total charge produced by the PE transducer in every cycle is given by:

$$
Q_{\text {total }}=2 I_{p} / \omega=2 C_{p} V_{p}
$$

The theoretical extracted power $P_{\text {OUT,calc }}$ from the PE transducer for every cycle is obtained by taking the available charge Equation (11) minus the various loss terms given by Equations (2), (6) and (10):

$$
\begin{aligned}
& P_{\text {OUT,calc }}=2 f_{p} V_{R E C T}\left(Q_{\text {total }}-Q_{C p}-Q_{R p 1}-Q_{R p 2}\right) \\
& =2 f_{p} V_{R E C T}\left\{\left[2 V_{p} C_{p}-\left[V_{R E C T}+2 V_{D}-V_{R E C T}\left(2 \eta_{f}-1\right)\right] C_{p}-\left[\frac{V_{p}}{\omega R_{p}}\left(\omega t_{2}-\sin \omega t_{2}\right)-\frac{V_{R E C T}}{\omega R_{p}}\right.\right.\right. \\
& \left.\left.\left(2 \eta_{f}-1\right) \omega t_{2}\right]-\left[\frac{V_{R E C T}+2 V_{D}}{R_{p}}\left(t_{\pi}-t_{2}\right)\right]\right\}
\end{aligned}
$$

\section{Measured Results}

The proposed rectifiers are fabricated in a one-poly six-metal $0.18 \mu \mathrm{m}$ CMOS process with a top $2 \mu \mathrm{m}$ thick metal option. Figure 8 shows the chip microphotographs. The size of the rectifiers using LDDE and MDDE are $0.26 \mathrm{~mm} \times 0.19 \mathrm{~mm}$ and $0.51 \mathrm{~mm} \times 0.46 \mathrm{~mm}$, respectively. Figure 9 shows the experimental setup to characterize the rectifier using the PE transducer.

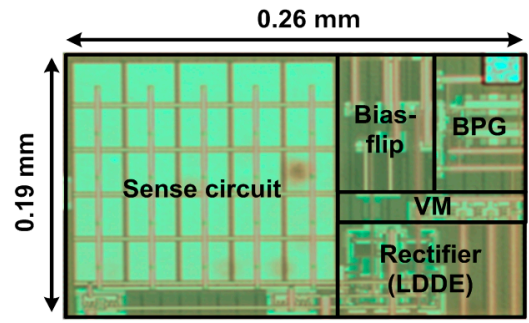

(a)

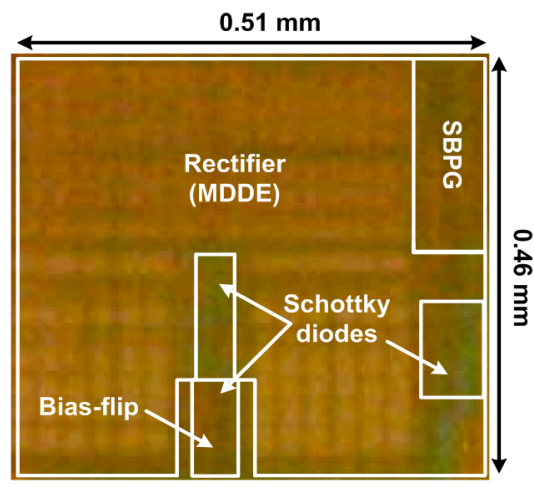

(b)

Figure 8. Chip micrograph of the resonant rectifier ICs using (a) LDDE; and (b) MDDE.

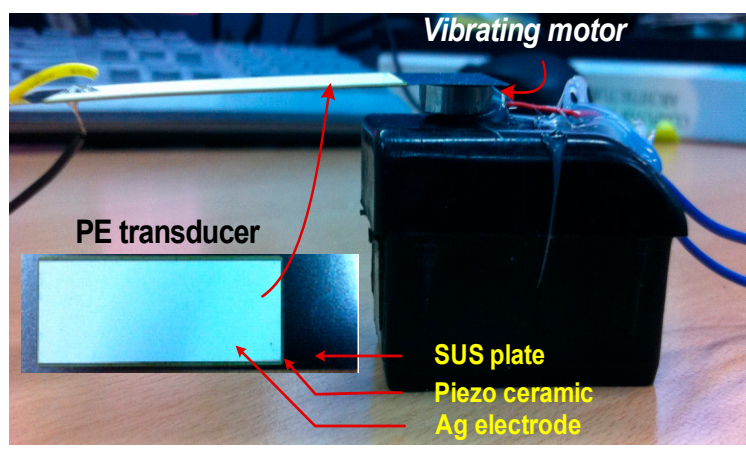

Figure 9. Experimental setup.

The bimorph of the transducer has a thickness, a length and a width of $0.33,75$, and $20 \mathrm{~mm}$, respectively [16]. Each layer consists of a stainless steel (SUS) plate, a piezo ceramic, and an $\mathrm{Ag}$ electrode. The PE transducer is mounted on a vibrating motor for mechanical excitement [17]. The transducer is excited using $200 \mathrm{~Hz}$ with an acceleration of $1.8 \mathrm{~g}$. Under this condition, the theoretical optimum loading resistance of the PE transducer is $7.2 \mathrm{k} \Omega$. Two wires attached to both sides of the transducer are interfaced with a test board containing the rectifiers. Table 2 shows the 
parameters used for the experiment. The value of the inductor for bias-flip is selected considering the trade-off between size and the Q-factor. The maximum current available from the transducer is $600 \mu \mathrm{A}$, which corresponds to $V_{p}=4.34 \mathrm{~V}$ at $200 \mathrm{~Hz}$. The equivalent circuit of a PE transducer can be represented as a mechanical spring-mass coupled to an electrical circuit. The current in the primary mechanical side corresponds to proof mass relative velocity, which is determined by such parameters as PE material, dimension, and acceleration. By the electromechanical coupling factor, which describes the effectiveness of the conversion from mechanical to electrical energies, the maximum current is determined.

Table 2. Parameters for the experiment.

\begin{tabular}{cc}
\hline Parameters & Value \\
\hline$f_{p}$ & $200 \mathrm{~Hz}$ \\
$C_{p}$ & $110 \mathrm{nF}$ \\
$R_{p}$ & $1 \mathrm{M} \Omega$ \\
$L_{G 1}, L_{G 2}, L_{G 3}$ & $1000 \mu \mathrm{H}$ \\
$C_{L}$ & $1 \mu \mathrm{F}$ \\
$R_{L}$ & $10-200 \mathrm{~K} \Omega$ \\
\hline
\end{tabular}

Figure 10 shows the measured result of the rectifier using LDDE. It shows the input voltage $V_{P N}$, bootstrap pulse signals $V_{S W 1}$ and $V_{S W 2}$, and the output $V_{R E C T}$. The transient during self-startup is shown in the inset. When $V_{P N}$ is increased, the BPG starts generating $V_{S W 1}$ and $V_{S W 2}$. Then, $V_{R E C T}$ starts increasing and the steady-state condition is reached at about $20 \mathrm{~s}$. After this time, $V_{S W 1}$ and $V_{S W 2}$ reach a value about twice that of the multiplier output and fully turn on the bias-flip circuit.

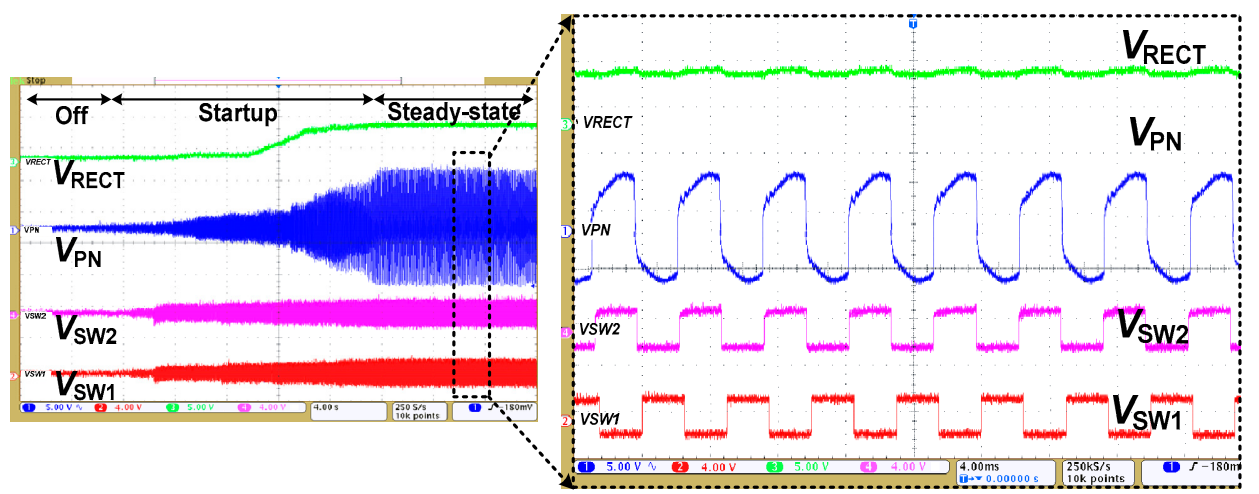

Figure 10. Measured waveforms of the resonant rectifier using LDDE.

Figure 11 shows the measured and calculated $P_{\text {OUT }}$ and efficiency versus $V_{R E C T}$. We characterize the rectifier under external and self-power conditions. When it is externally powered, the VM provides power only to the BPG and the internal oscillator is turned off. The CLK frequency is supplied externally to match the $f_{p}$ of the PE transducer. By receiving the CLK, the BPG generates $V_{S W 1}$ and $V_{S W 2}$. The $V_{\text {RECT }}$ is measured with $I_{P}=600 \mu \mathrm{A}$. Since $V_{R E C T}$ depends on $R_{L}$, it is varied from 10 to $200 \mathrm{k} \Omega$, searching for an optimum value. When $V_{R E C T}$ reaches $3.36 \mathrm{~V}$, the measured peak $P_{\text {OUT }}$ of $564 \mu \mathrm{W}$ is achieved with an $R_{L}$ of $20 \mathrm{k} \Omega$. The $P_{\text {OUT,calc }}$ obtained using Equation (12) is $626 \mu \mathrm{W}$, which indicates that the power consumed by the control circuit is $62 \mu \mathrm{W}$. The maximum input power which can be delivered by the PE transducer is obtained as $P_{I N}=2 C_{p} f_{p}\left(V_{p}\right)^{2}=828 \mu \mathrm{W}$. Using the definition for power transfer efficiency $=P_{\text {OUT }} / P_{I N}$, we obtain $68.1 \%$. Using the measured $V_{f}$ of $1.53 \mathrm{~V}$ in Equation (1), a flipping efficiency $\eta_{f}$ of $72.8 \%$ is achieved. Under the same PE input condition and with $V_{D}=0.7 \mathrm{~V}$, the maximum power that can be obtained using the FBR [2] is $190 \mu \mathrm{W}$. The results show that the rectifier using LDDE delivers three times higher $P_{\text {OUT }}$ than that of the FBR. 


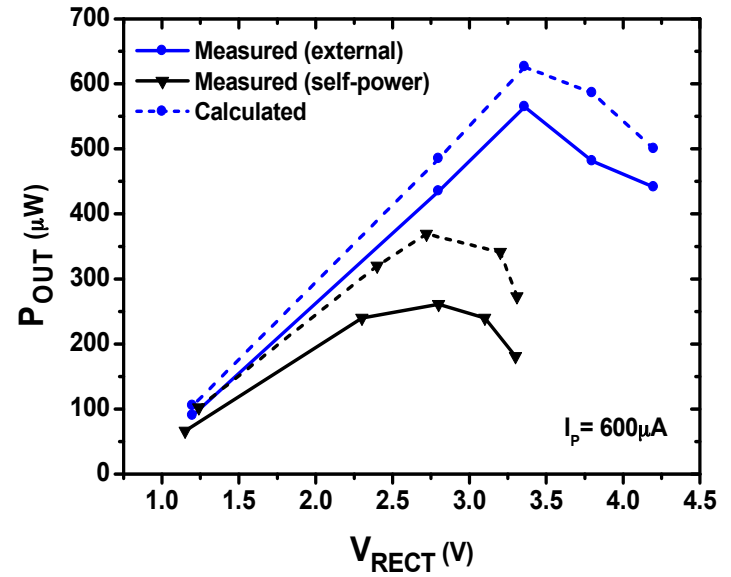

(a)

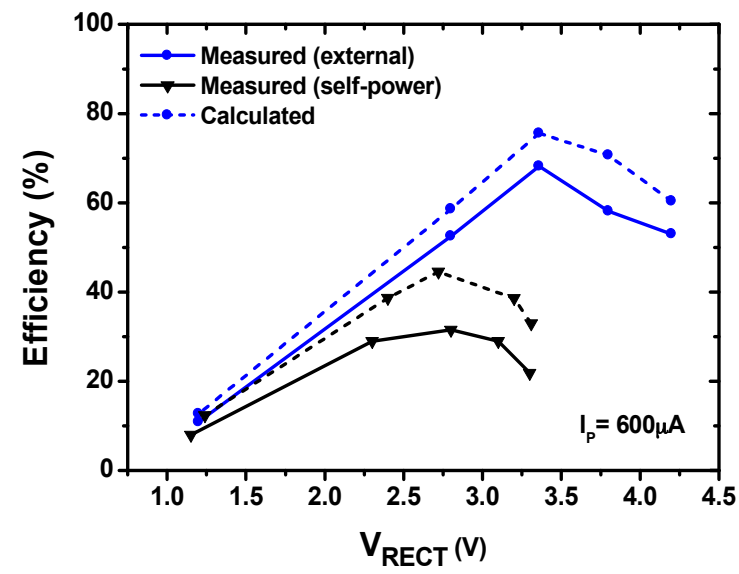

(b)

Figure 11. Performance of the rectifier using LDDE: (a) output power versus output voltage; and (b) power transfer efficiency versus output voltage.

Under the self-power condition, a resistive voltage divider is placed at the output of the VM. The role of the divider is controlling the supply voltage of OSC, which determines the CLK. The voltage divider is tuned so that the CLK frequency is closely matched to the $f_{p}$ of PE transducer. The results show a $P_{\text {OUT }}$ of $261 \mu \mathrm{W}$ with a $V_{\text {RECT }}$ of $2.8 \mathrm{~V}$.

Figure 12 shows the measured waveform of the rectifier using MDDE. The result shows the initial transient waveform during self-startup. When $V_{P N}$ starts increasing, the SBPG generates pulses for the bias-flip. After the steady-state condition is reached at about $2 \mathrm{~s}, V_{\mathrm{PN}}$ flips abruptly. Figure 13 shows the measured and calculated $P_{\text {OUT }}$ and efficiency versus $V_{R E C T}$ for two cases: $I_{P}=600 \mu \mathrm{A}$ and $400 \mu \mathrm{A}$. The rectifier is characterized by varying $R_{L}$ from 10 to $200 \mathrm{k} \Omega$ to find an optimum condition. Using $I_{P}=400 \mu \mathrm{A}$, a peak $P_{\text {OUT }}$ of $288 \mu \mathrm{W}$ and a $V_{R E C T}$ of $2.4 \mathrm{~V}$ are extracted with an $R_{L}$ of $20 \mathrm{k} \Omega$, which corresponds to an efficiency of $78.4 \%$. The $P_{\text {OUT,calc }}$ obtained using Equation (12) is $386 \mu \mathrm{W}$, which indicates that the additional loss and control power is $98 \mu \mathrm{W}$. Since $P_{\text {OUT }}$ depends on the PE transducer characteristics and the mechanical vibration $[18,19]$, it is difficult to directly compare $P_{\text {OUT }}$ performance (See Table 3). However, the conventional FBR can be used as a common reference. Under the same conditions, the maximum power that can be obtained using the FBR is $48.8 \mu \mathrm{W}$. The results show that the rectifier using MDDE delivers 5.9 times higher $P_{\text {OUT }}$ than that of the FBR. Using $I_{P}=600 \mu \mathrm{A}$, a $P_{\text {OUT }}$ of $441 \mu \mathrm{W}$ is extracted with a $V_{R E C T}$ of $2.1 \mathrm{~V}$ using an $R_{L}$ of $10 \mathrm{k} \Omega$. The result shows that efficiency is reduced when $I_{P}$ is increased from 400 to $600 \mu \mathrm{A}$. This is related to the narrow working window where $V_{\mathrm{D}}$ is increased with $I_{P}$ (See Figure 6).

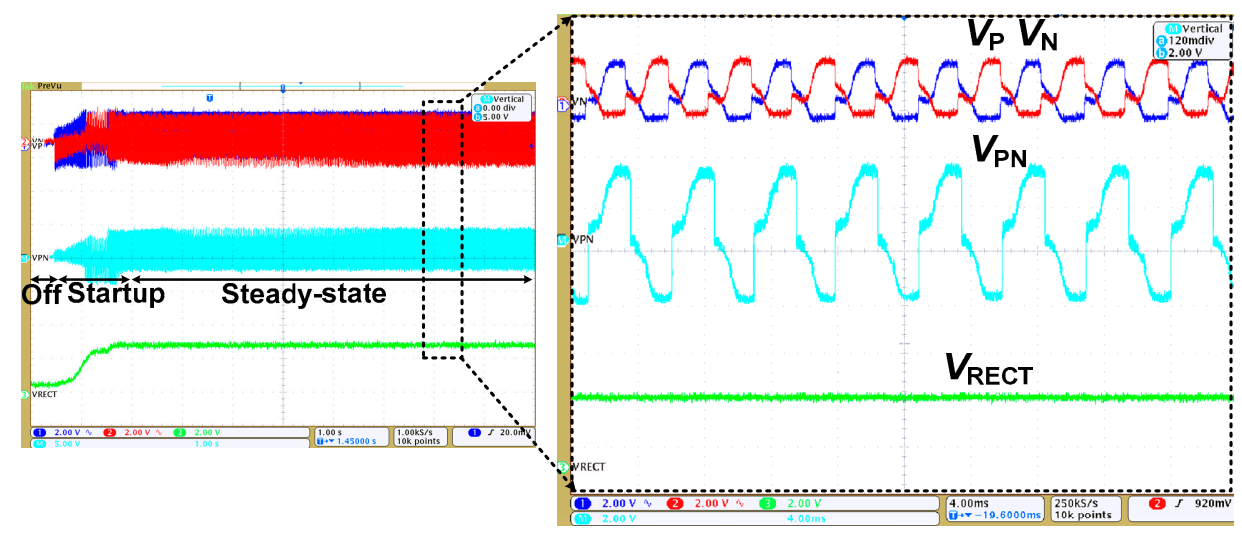

Figure 12. Measured waveforms of the resonant rectifier using MDDE. 


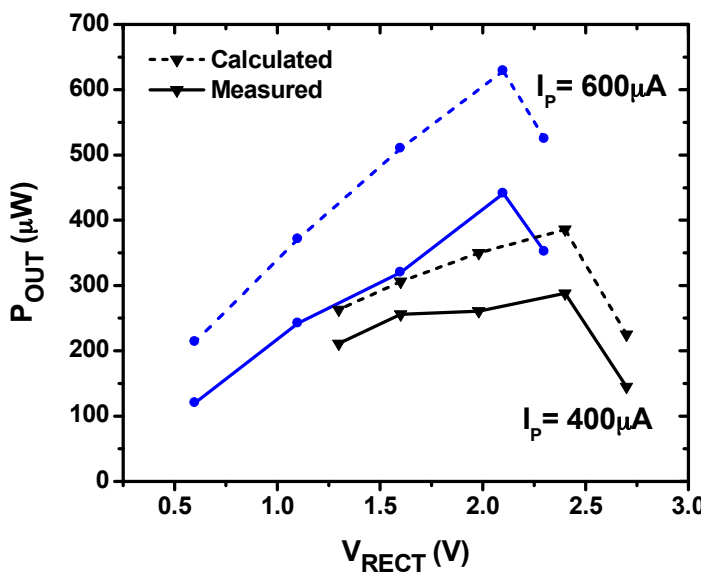

(a)

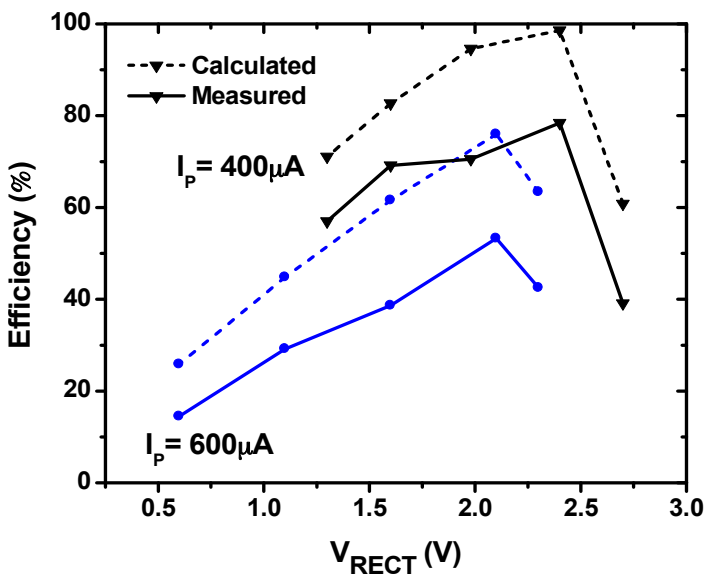

(b)

Figure 13. Performance of the rectifier using MDDE for two $I_{P}$ values: (a) output power versus output voltage; and (b) power transfer efficiency versus output voltage.

Table 3 shows a performance comparison with previous works realized using IC technology. The work in [2] presents a resonant rectifier using the bias-flip technique. The bias-flip timing is controlled by a digital inverter delay line that can be programmed externally. Although the adjustable delay control provides flexibility to accommodate various PE transducers, self-startup is not supported. Further, the efficiency of $58 \%$ is rather low, which can be attributed to the voltage drop in bias-flip switches and rectifying stages. In [4], a passive differentiator is used to detect the $I_{P}$ polarity change. In this work, two separate paths are used to reduce the voltage drop for bias-flip. A relatively high $P_{\text {OUT }}$ of $1230 \mu \mathrm{W}$ is achieved under externally-powered conditions. The work in [6] proposes a parallel synchronized switch harvesting on inductor (P-SSHI) technique which extracts $48 \mu \mathrm{W}$. The result in [20] shows a high efficiency of 91\%. Including [20], however, the results in [4,6] are based on discrete realization and not included for comparison.

Table 3. Performance comparison with previous works.

\begin{tabular}{|c|c|c|c|c|c|c|c|c|}
\hline & \multicolumn{2}{|c|}{ This Work } & \multirow[b]{2}{*}{ [2] } & \multirow[b]{2}{*}{ [3] } & \multirow[b]{2}{*}{ [21] } & \multirow[b]{2}{*}{ [22] } & \multirow[b]{2}{*}{ [23] } & \multirow[b]{2}{*}{ [24] } \\
\hline & $\begin{array}{l}\text { Rectifier } \\
\text { (MDDE) }\end{array}$ & $\begin{array}{l}\text { Rectifier } \\
\text { (LDDE) }\end{array}$ & & & & & & \\
\hline Tech. & \multicolumn{2}{|c|}{$0.18 \mu \mathrm{m}$} & $0.35 \mu \mathrm{m}$ & $0.18 \mu \mathrm{m}$ & $0.18 \mu \mathrm{m}$ & $0.35 \mu \mathrm{m}$ & $0.35 \mu \mathrm{m}$ & $0.25 \mu \mathrm{m}$ \\
\hline Type & \multicolumn{2}{|c|}{$\begin{array}{c}\text { Bias-flip/diode } \\
\text { equivalent }\end{array}$} & Bias-flip & Active FBR & S-SSHI & Energy Invest & Inductor-less & SSHI \\
\hline$V_{P}(\mathrm{~V})$ & 2.89 & 4.34 & 2.8 & 2.8 & 2.2 & 2.6 & 2.5 & 4.9 \\
\hline$f_{0}(\mathrm{~Hz})$ & \multicolumn{2}{|c|}{200} & 225 & 200 & 200 & 143 & 82 & 144 \\
\hline PE transducer & \multicolumn{2}{|c|}{ Thrive K7520BP2 } & V22B Mide & Circuit model & Circuit model & V22B Mide & V22W Mide & V22B Mide \\
\hline Self-power & $Y$ & $\mathrm{~N}$ & $\mathrm{~N}$ & $\mathrm{~N}$ & $\mathrm{Y}$ & $\mathrm{N}$ & $\mathrm{N}$ & $\mathrm{Y}$ \\
\hline$V_{R E C T}(\mathrm{~V})$ & 2.4 & 3.36 & 3.2 & 2.78 & 3.6 & 3.7 & 1.0 & 3.9 \\
\hline$P_{\text {OUT }}(\mu \mathrm{W})$ & 288 & 564 & 53 & 81 & 74 & 52 & 35 & 136 \\
\hline Efficiency (\%) & 78.4 & 68.1 & 58 & 90 & 89.5 & 69 & 77 & 85 \\
\hline
\end{tabular}

The work in [21] presents a series synchronized switch harvesting on inductor (S-SSHI) technique, which is applied to the conventional FBR. It shows a good efficiency of $89.5 \%$. However, the results in $[3,21]$ are obtained using an equivalent model of the PE transducer, therefore, its performance in a real environment is unknown. The work in [22] increases power extraction by investing energy from the battery to enhance the electromechanical coupling factor. The work in [23] presents a fully-integrated interface to a PE transducer which does not employ an inductor. By dynamically switching between parallel and series configurations of two PE transducers, this work achieves a peak efficiency of 
$77 \%$. The work in [24] inserts an active diode in the resonant loop of the SSHI circuit which allows bias-flipping to occur at an optimal time without the need for complicated delay-tuning circuits. In the proposed rectifier using LDDE, we achieve an efficiency of $68.1 \%$ under the external-power condition. Under the self-power condition, the rectifier using MDDE delivers a $P_{\text {OUT }}$ of $288 \mu \mathrm{W}$ and a $V_{R E C T}$ of $2.4 \mathrm{~V}$. This corresponds to an efficiency of $78.4 \%$. Although this efficiency number is lower than the results of [24], a $P_{\text {OUT }}$ of $441 \mu \mathrm{W}$ is extracted using $I_{P}=600 \mu \mathrm{A}$, demonstrating the high power extraction capability of the proposed work. The results indicate the improvement is achieved using efficient bias-flipping with a low $V_{\mathrm{D}}$ of the MDDE.

\section{Conclusions}

In this work, we presented an efficient rectifier design technique for PE energy harvesting. To reduce the voltage drop in the rectifier, two diode equivalents are proposed. The diode equivalents are successfully embedded in two resonant rectifiers using the symmetric bias-flip technique. In addition, time synchronization of the bias-flip with the PE transducer is studied. Further, we propose a self-power boosted pulse generator that synchronously detects the zero crossing transition of the PE transducer. The measured results show that the proposed rectifiers significantly increase the extracted power and efficiency. The rectifier using LDDE delivers a $P_{\text {OUT }}$ of $564 \mu \mathrm{W}$ with a corresponding efficiency of $68.2 \%$. The rectifier using MDDE delivers a $P_{\text {OUT }}$ of $288 \mu \mathrm{W}$ with a peak efficiency of $78.4 \%$. Compared to the conventional FBR, these results show that the rectifier using MDDE and LDDE achieves a power extraction capability enhanced by factors of 5.9 and three times, respectively. The results indicate that an improvement is achieved with the proposed diode equivalents. This result can play a valuable role in various sensing applications that demand energy harvesting to obtain auxiliary power for extended battery lifetime.

Acknowledgments: This research was supported by the Basic Science Research Program through the National Research Foundation (NRF) of Korea (No. 2015R1A2A2A03004160).

Author Contributions: Amad Ud Din designed the resonant rectifiers and setup, performed the experimental work, and wrote the manuscript. Seneke Chamith Chandrathna supplied input to the rectifier operation and performed simulations. Jong-Wook Lee conceived the project, organized the paper content, and edited the manuscript.

Conflicts of Interest: The authors declare no conflict of interest.

\section{References}

1. Roundy, S. Energy Scavenging for Wireless Sensor Networks with Special Focus on Vibrations; Kluwer Academic Press: Dordrecht, The Netherlands, 2003.

2. Ramadass, Y.K.; Chandrakasan, A.P. An efficient piezoelectric energy harvesting interface circuit using a bias-flip rectifier and shared inductor. IEEE J. Solid State Circuits 2010, 45, 189-204. [CrossRef]

3. Sun, Y.; Hieu, N.H.; Joeng, C.J.; Lee, S.G. An integrated high-performance active rectifier for piezoelectric vibration energy harvesting system. IEEE Trans. Power Electron. 2012, 27, 623-627. [CrossRef]

4. Krihely, N.; Ben-Yaakov, S. Self-contained resonant rectifier for piezoelectric sources under variable mechanical excitation. IEEE Trans. Power Electron. 2011, 26, 612-621. [CrossRef]

5. Lefeuvre, E.; Badel, A.; Richard, C.; Guyomar, D. A comparison between several vibration-powered piezoelectric generators for standalone systems. Sens. Actuators A Phys. 2005, 126, 405-416. [CrossRef]

6. Lu, S.; Boussaid, F. A highly efficient P-SSHI rectifier for piezoelectric energy harvesting. IEEE Trans. Power Electron. 2015, 30, 5364-5369. [CrossRef]

7. Umeda, T.; Yoshida, H.; Shuichi, S.; Fujita, F.; Suzuki, T.; Otaka, S. A 950-MHz rectifier circuit for sensor network tags with 10-m distance. IEEE J. Solid State Circuits 2006, 1, 35-41. [CrossRef]

8. Guo, S.; Lee, H. An efficiency-enhanced CMOS rectifier with unbalanced-bias comparators for transcutaneous power high-current implants. IEEE J. Solid State Circuits 2009, 44, 1796-1804. [CrossRef]

9. Damascheke, J. Design of a low-input-voltage converter for the thermoelectric generator. IEEE Trans. Ind. Appl. 1997, 33, 1203-1207. [CrossRef] 
10. Ramadass, Y.K.; Chandrakasan, A.P. A battery-less thermoelectric energy harvesting interface circuit with $35 \mathrm{mV}$ startup voltage. IEEE J. Solid State Circuits 2011, 46, 333-341. [CrossRef]

11. Chen, P.H.; Ishida, K.; Ikeuchi, K.; Zhang, X.; Honda, K.; Okuma, Y.; Ryu, Y.; Takamiya, M.; Sakurai, T. Startup techniques for $95 \mathrm{mV}$ step-up converter by capacitor pass-on scheme and $V_{\mathrm{TH}}$-tuned oscillator with fixed charge programming. IEEE J. Solid State Circuits 2012, 47, 1252-1260. [CrossRef]

12. Kim, J.; Mok, P.K.T.; Kim, C. A 0.15 V-input energy harvesting charge pump with switching body biasing and adaptive dead-time for efficiency improvement. IEEE J. Solid State Circuits 2015, 50, 414-425. [CrossRef]

13. Lee, J.-W.; Lee, B.; Kang, H.B. A high sensitivity, $\mathrm{CoSi}_{2}-\mathrm{Si}$ Schottky diode voltage multiplier for UHF-band passive RFID tag chips. IEEE Microw. Wirel. Compon. Lett. 2008, 18, 830-832. [CrossRef]

14. Din, A.U.; Chung, D.; Park, D.; Lee, H.; Lee, J.-W. A high extraction self-controllable CMOS resonant rectifier circuit for piezoelectric energy scavenging system. In Proceedings of the 2014 International SoC Design Conference (ISOCC), Jeju, Korea, 3-6 November 2014; pp. 40-41.

15. Karthikeyan, L.; Amrutur, B. Signal-powered low-drop-diode equivalent circuit for a full-wave bridge rectifier. IEEE Trans. Power Electron. 2012, 27, 4192-4201. [CrossRef]

16. Piezo-Electric Energy Harvesting THRIVE. Available online: http://www.thrive.co.jp./PDF/flyer_KINEZ_ K7520BS2/BP2.pdf (accessed on 9 December 2016).

17. Tokyo Parts Industrial Co. Model FM34F vibration motor. Available online: http://gemart.co.kr/files/ FM34F.pdf?PHPSESSID=3cc3e64e513e692acdf2ac974840f318 (accessed on 15 December 2016).

18. Caliò, R.; Rongala, U.; Camboni, D.; Milazzo, M.; Stefanini, C.; de Petris, G.; Oddo, C. Piezoelectric energy harvesting solutions. Sensors 2014, 14, 4755-4790. [CrossRef] [PubMed]

19. Dicken, J.; Mitcheson, P.D.; Stoianov, I.; Yeatman, E.M. Power-extraction circuits for piezoelectric energy harvesters in miniature and low-power applications. IEEE Trans. Power Electron. 2012, 27, 4514-4529. [CrossRef]

20. Lu, S.; Boussaid, F. An inductorless self-controlled rectifier for piezoelectric energy harvesting. Sensors 2015, 15, 29192-29208. [CrossRef] [PubMed]

21. Do, X.-D.; Nguyen, H.H.; Han, S.K.; Lee, S.-G. A rectifier for piezoelectric energy harvesting system with series synchronized switch harvesting inductor. In Proceedings of the 2013 IEEE Asian Solid-State Circuits Conference (A-SSCC), Singapore, 11-13 November 2013; pp. 10-13.

22. Kwon, D.; Rincón-Mora, G.A. A single-inductor $0.35 \mu \mathrm{m}$ CMOS energy-investing piezoelectric harvester. IEEE J. Solid State Circuits 2014, 49, 2277-2291. [CrossRef]

23. Du, S.; Jia, Y.; Seshia, A.A. An efficient inductorless dynamically configured interface circuit for piezoelectric vibration energy harvesting. IEEE Trans. Power Electron. 2017, 32, 3595-3609. [CrossRef]

24. Wu, L.; Do, X.D.; Lee, S.G.; Ha, D.S. A self-powered and optimal SSHI circuit integrated with an active rectifier for piezoelectric energy harvesting. IEEE Trans. Circuits Syst. I Regul. Pap. 2017, 64, 537-549. [CrossRef]

(C) 2017 by the authors. Licensee MDPI, Basel, Switzerland. This article is an open access article distributed under the terms and conditions of the Creative Commons Attribution (CC BY) license (http:/ / creativecommons.org/licenses/by/4.0/). 